\title{
Assessment of the mutual influence of deformation-strength characteristics of the fastening system elements
}

\author{
Iryna Kovalevska ${ }^{1 *}$, Zenon Pilecki ${ }^{2}$, Oleksandr Husiev $^{3}$, and Vasyl Snihur ${ }^{4}$ \\ ${ }^{1}$ Dnipro University of Technology, Department of Underground Mining, 19 Yavornytskoho Ave., \\ 49005 Dnipro, Ukraine \\ ${ }^{2}$ Mineral and Energy Economy Research Institute of the Polish Academy of Sciences, 7 Wybickiego \\ St., 31-261 Krakow, Poland \\ ${ }^{3}$ MM "Dniprovske", PJSC "DTEK Pavlohradvuhillia", 76 Soborna Ave., 51400 Pavlohrad, Ukraine \\ ${ }^{4}$ MM "Heroiv Kosmosu", PJSC "DTEK Pavlohradvuhillia", 76 Soborna Ave., 51400 Pavlohrad, \\ Ukraine
}

\begin{abstract}
The degree of influence has been determined of diversified deformation-strength characteristics of load-bearing elements in the fastening system of the preparatory mine workings, while maintaining them in a laminal massif of soft rocks. The analysis has been performed of multivariate computational experiments of the stress-strain state of the load-bearing elements of the fastening system in the preparatory mine workings from the position of the mutual influence of their deformationstrength characteristics and the support loading as a whole. An analysis is represented of the mutual influence of the operation modes of the mine working support elements between themselves and the fastening system as a whole; it has been studied the stress-strain state of the mine working fastening system with a central hydraulic prop stay, as well as a significant increase in reliability of the support performance has been analysed and determined. The tendency has been substantiated of minimizing the load on the mine working fastening system - increasing the coherence of the diversified operation modes of fastening elements by enhancing preferentially the yielding property of the rigid element. The application has been substantiated of the central yielding prop stays of the strengthening support of a frame in case of intensive rock pressure manifestation in the zone of the stope works active influence.
\end{abstract}

\section{Introduction}

When studying and generalizing the tendencies of the main geomechanical factors influence on the fastening system state [1-4], it has been repeatedly observed a certain mutual influence on each other of the elements included into the scheme for maintaining the preparatory mine workings. And the degree of this influence mostly depended on how different their operation modes are in the process of resistance to the rock pressure

\footnotetext{
*Corresponding author: kovalevska_i@yahoo.com
} 
manifestations. For example, if the yielding and rigid elements are interacting (the cap board of the yielding frame and the central wooden prop stay of the strengthening support), then usually in the area of their contact in the yielding element [5], the significant disturbances of stresses components occur, which often reach the destructive values [6]. Therefore, it is very important the issue of coherency between the deformation-strength characteristics of the elements included into the fastening system [7], against their general adaptation to the nature of the rock pressure manifestations, which is conditioned by the action of a geomechanical factors combination [7-11]. In this connection, the analysis of multivariate modelling results constantly indicates the different degree of loading of individual elements [12], regardless of the geomechanical factors action and the reason for this is the different operation mode of the compared elements of fastening systems: more yielding deformation-strength characteristic provides a reduced load compared to a more rigid characteristic of the fastening element resistance $[13,14,16]$. But, if these elements are the elements of the same fastening system and resist to one and the same displacement process of the coal-overlaying formation, the unloading of the more yielding element increases the load on the more rigid element and this different-sized loading can lead to the destruction (or partial loss of load-bearing capacity), first of all, of the most rigid elements of the fastening system, and then (by a "chain reaction") of all the rest elements. In this regard, a problem of equal strength of fastening systems elements, in particular, developed in $[13,15]$, acquires a new significance, but, which is now considered from the point of view of coherency between the deformation-strength characteristics of all the main loadbearing elements of a single fastening system.

The concept of equal strength as applied to fastening systems of mine workings, means the taking up by separate elements of loads, which are proportional to their load-bearing capacity [17]. Then, in the boundary situation, the limiting state occurs simultaneously in all load-bearing elements, which reflects the condition for achieving the maximum resistance of the fastening system as a whole. Otherwise, (unequal strength) a similarity to chain reaction occurs according to the following scheme:

- at first, the most loaded element loses the load-bearing capacity long before achieving the maximum load-bearing capacity by the fastening system as a whole;

- the load on an element, which has been out of order, is redistributed to the remaining fastening system components and the most rigid of them, as a rule, becomes overloaded and also is destroyed;

- then, the remaining components of the fastening system one after another lose their stability, with the value of its overall reaction, which is far from the potential maximum of the load-bearing capacity.

Thus, the equal strength principle of the non-uniform fastening system in terms of the deformation-strength characteristics of its elements, is one of the conditions for increasing the effectiveness of its resistance to rock pressure [18, 19].

As a result, it is possible to distinguish two types of mutual influence on each other of the fastening system elements with different deformation-strength characteristics:

- direct influence, when the separate elements are structurally interconnected [20];

- indirect influence, when separate elements, although are not structurally connected with each other, but indirectly effects each other through the displacement processes of the coal-bearing massif [21]. As an example of a direct connection may serve such combinations as: the frame prop stays are connected with lateral roof-bolts by the rope spatially pliable longitudinal binders; the frame cap board which is connected with the prop stay by means of a yielding joist, and some other examples. The indirect mutual influence occurs in cases of the use of combined means of mine workings fastening, for example, with bearing roof-bolting [22], when the roof-bolts and the frame are not connected with each other structurally $[23,24]$. Both types of mutual influence are presented in works $[25,26]$, when 
analysing the results of the multivariate modelling of the fastening system state of the drifts, maintained behind the longwall face in a laminal rock massif with a low hardness. But, in paper [1] the mechanism is described of mutual influence of the load-bearing elements of the fastening system in the preparatory mine workings with different deformation-strength characteristics, developed on the basis of the development of concepts about the interaction of mine working with the surrounding massif.

\section{Main part}

\subsection{Influence of the mediated interaction of support system elements}

The conditions have been studied of the indirect mutual influence of the load-bearing elements of the system with a more rigid (index " $r$ ") and more yielding (index " $y$ ") deformation-strength characteristic in terms of formation of the load on them and search for ways of its minimization. This process is represented in Fig. 1, where the full lines reflect the deformation-strength characteristics of the weakening massif (dependence 1) and the rocks of the dome of natural equilibrium (dependence 2); the dashed lines show the deformation-strength characteristics of fastening system elements (in a more rigid " $r$ " and in a more yielding " $y$ "); the dash-dotted lines represent the deformation-strength characteristics (index ' $f$ ") of the fastening system as a whole.

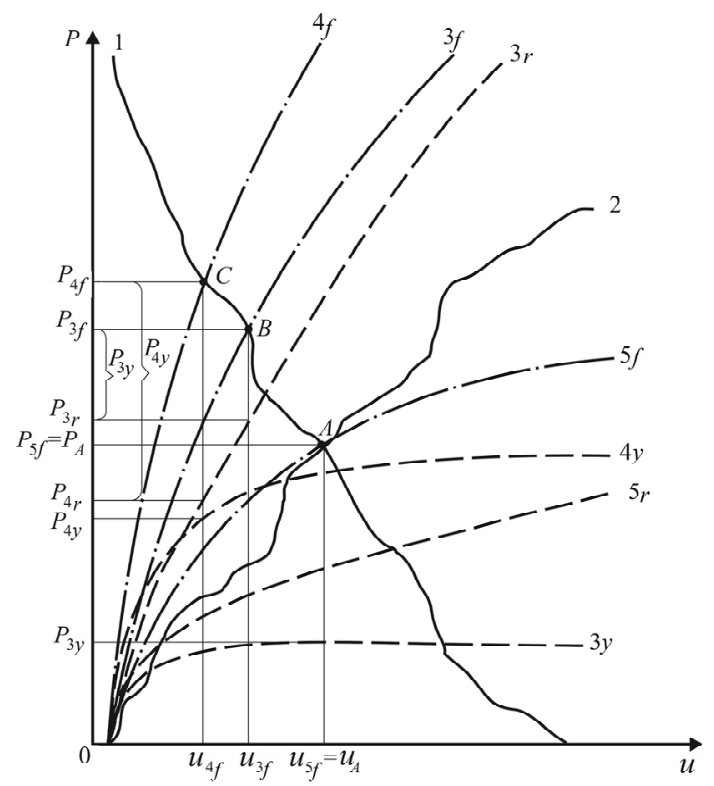

Fig. 1. The diagram of the ways of coherency between the operation modes of a more rigid (index " $r$ ") and more yielding (index " $y$ ") fastening system elements in the preparatory mine working: 1 and 2 - the deformation-strength characteristics of the weakening massif and rocks of the dome of natural equilibrium, respectively; - - - the deformation-strength characteristics of a rigid and a yielding fastening elements; - - - the deformation-strength characteristics of the system as a whole.

The initial structural design of the fastening system includes a more yielding element with the deformation-strength characteristic $3 y$ and a more rigid element with the deformation-strength characteristic $3_{r}$; the resultant of their joint resistance is represented by the deformation-strength characteristic $3_{f}$ of the fastening system as a whole. The load $P_{3 f}$ on the fastening system with its required yielding property $u_{3 f}$, is determined by $B$ point 
of lines 1 and $3_{f}$ intersection. The value of the minimum permissible fastening system resistance $P_{3 f}$ includes the resistance $P_{3 r}$ of a more rigid element and the resistance $P_{3 y}$ of a more yielding element with the displacements value $u_{3 f}$. As it can be seen, the total deformation-strength characteristic of the fastening system is not optimal, since it does not pass through the point $A$ of the lines 1 and 2 intersection; therefore, the load $P_{3 f}$ is significantly higher than the optimal value $P_{A}$.

The coherence of the operation modes of this fastening system elements can be performed in two ways: to increase the "rigidit" of the deformation-strength characteristics of a more yielding fastening element or to increase the yielding property of a more rigid one. In principle, there is a third way - a simultaneous change in the operation mode of both fastening elements, but then both of them should be exposed to structural changes.

Let us study the way of increasing the rigidity of a more yielding fastening element, which is now represented by the line $4_{y}$. The term "increasing the rigidity of operation mode" means "increasing the resistance reaction of a fastening element" with the same value of its yielding property, i.e. $P_{4 y}>P_{3 y}$ (see. Fig. 1). Then the total deformationstrength characteristic of the fastening system as a whole (line $4_{f}$ ) will also become more rigid and the load being formed on it is determined by the point $C$ of intersection with the line 1. As it can be seen from the diagram, $P_{4 f}>P_{3 f}$, therefore, the way of increasing the operation mode rigidity of a more yielding fastening element is irrational, since it leads to an increase in the load of the fastening system.

The way of increasing the yielding property of a more rigid fastening element is represented by the line $5_{r}$, which corresponds to the ideal variant of the general deformation-strength characteristics of the fastening system (line $5_{f}$ ), passing through the $A$ point of the lines 1 and 2 intersection, and which reflects the minimum possible load formation on the fastening system $P_{5 f}=P_{A}$.

Thus, the second way is more preferable in the direction of increasing the degree of coherency between the very operation modes of fastening elements with different deformation-strength characteristics. This example evidences the following conclusion: the coherence of operation modes of fastening elements should be conducted in the direction of minimizing the load on the fastening system as a whole [27], and the question concerning the difference between the deformation-strength characteristics of separate load-bearing elements, is a secondary one [28-]. At the same time, it should be noted that the criterion for minimizing the load on the fastening system is only one of the conditions for the rational improvement of operation modes through these or other structure changes.

There is one more important issue (equally relevant as with the direct and indirect influence on each other of the fastening system elements) of choosing the time and distance to the stope face, when it is most expedient to strengthen the fastening system with additional load-bearing elements; for example, the frame support of the SCP special profile is strengthened with the central and side prop stays with different way of construction. Moreover, this issue is considered from the point of view of the degree of coherency of the deformation-strength characteristics of the original fastening system and the means of its strengthening.

The matter point of the studied problem is represented in Fig. 2, where the same indications are used (as in Fig. 1) of the diagrams reflecting the deformation-strength characteristics of the weakening massif and the rocks of the dome of natural equilibrium ( 1 and 2 lines), yielding and rigid fastening elements ( $3_{y}$ and $3_{r}$ lines) and the strengthened fastening system as a whole (lines $3_{f}$ ).

Further on, a change is considered in the modes of interaction between the fastening system as a whole and the massif in the dynamics of development of the rock pressure manifestations as the stope face approaches and recedes. Outside the zone of stope works influence and with relatively low displacements of the rock contour of the $\operatorname{drift}\left(u<u_{D}\right)$, the 
original fastening system (for example, frame support) copes with the load of the weight of rocks inside the dome of natural equilibrium (the line $3_{y}$ is above the line 2), owing to the yielding property of a frame, it "deviates" from the excessive rock pressure conditioned by the increase in the volume of the weakening massif (line 1).

As the longwall face approaches, the rock pressure manifestations are intensified in the form of increase in the rock contour displacements of the drift and in the load on the support. At a certain point of time and at a certain distance to the longwall face (point $D$ ), the load on the support $P_{D}$ is being equated with the value of its reaction, and this occurs during displacement $u_{D}$. This equilibrium state has a short duration, since the stope face advance has consistently intensified the rock pressure manifestations. Therefore, the original frame support needs to be strengthened, for example, with wooden prop stays, which is quite widespread in practice in the bearing pressure zone at some distance ahead of the longwall face. Here, there is a pressing question: at what distance from the longwall face it is necessary to strengthen the frame support and three variants are considered in the general case.

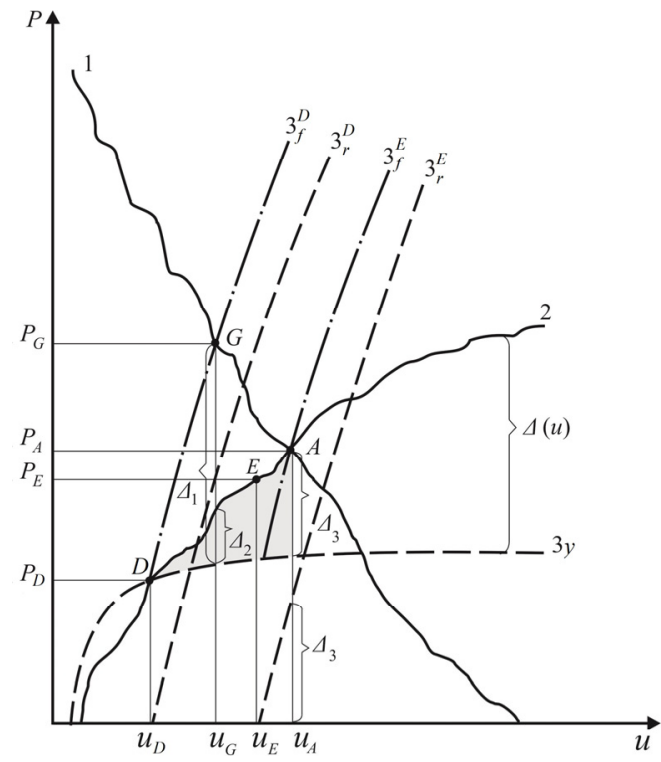

Fig. 2. The diagram to the choice of the deformation-strength characteristics of the strengthening support and the moment of its setting: 1 and 2 - the deformation-strength characteristics of the weakening massif and rocks of the dome of natural equilibrium, respectively; - - -the deformationstrength characteristics of a rigid (prop stay of the strengthening support) and a yielding (frame support) fastening elements; - - - the deformation-strength characteristics of the fastening system as a whole.

In the first variant, the prop stays of the strengthening support (with a sufficiently rigid deformation-strength characteristic) are set in the point $D$ where the frame support cannot longer provide adequate stability of the drift. The rigid deformation-strength characteristics of wooden prop stays (line $3_{r}^{D}$ ) with a slight increase in displacements of rocks in the drift roof, is able to develop a high resistance reaction, sufficient for the line $3_{f}^{D}$ of deformationstrength characteristics of the fastening system as a whole to be above the line 2 of rock weight within the dome of natural equilibrium and the stability of mine working is ensured. On the other hand, the setting of wooden prop stays makes more rigid the total deformation-strength characteristic of the fastening system with a corresponding increase in load $P_{G}$ on it, determined by the point $G$ of intersection of line 1 and $3_{f}^{D}$. Thus, with an 
increase in displacements $u_{G}-u_{D}$, the required increment in the fastening system reaction is a value $\Delta_{1}$, while an increase in the reactions only by an amount of $\Delta_{2}$ is quite sufficient, based on the condition of maintaining the rocks in the dome of natural equilibrium; this is caused by increased rigidity of the deformation-strength characteristics of the prop stays of the strengthening support.

The second variant of the frame support strengthening characterizes the tendency to form the minimum possible load on the fastening system, determined by the point $A$ of lines 1 and 2 intersection. To meet this condition, it is necessary that the deformation-strength characteristic of the fastening system (line $3_{f}^{E}$ ) passes through the point $A$, which, in turn, is possible if, at a value of displacements $u_{A}$, the increment in the fastening system reaction is $\Delta_{3}$ (see Fig. 2). Thus, the strengthening of the frame support should be performed in advance to the point $A$, namely, in the point $E$ with the corresponding parameters $P_{E}$ and $u_{E}$ of the rock pressure manifestations.

As it can be seen from the diagram, the load $P_{A}$ is significantly lower than $P_{G}$, but an obvious question arises, - how to ensure the stability of mine working in the range of displacements $u_{A}-u_{D}$ (from point $D$ to point $A$ ), since in this area the load from the weight of rocks in the dome of natural equilibrium (line 2) stably exceeds the fastening system reaction (at first the line $3_{y}$ in the area $D E$, and then the line $3_{f}^{E}$ in the area $E A$ ). This fact does not make possible to consider as positive the decision to strengthen the frame support when the displacements reach the value $u_{E}$. There, the following optimal solution arises, concerning not only the choice of the moment of the frame strengthening, but also the improvement of the deformation-strength characteristics of the prop stays of the strengthening support, which is distinguished as the third variant.

The matter point of the optimal solution is as follows:

- firstly, an excess should be avoided in load from the weight of the rocks in the dome of natural equilibrium over the frame support reaction; for this, the frame must be strengthened no later than a point $D$, that is, at $u \leq u_{D}$;

- secondly, the additional reaction $\Delta_{3}$ from the prop stays of the strengthening support should be the difference between the weight of rocks in the dome of natural equilibrium (line 2) and the frame reaction (line $3 y$ ) as the displacements $u$ develop in rock contour of the drift (in the process of the longwall face approaching); then this additional reaction can be considered as a function $\Delta(u)$ or as a deformation-strength characteristic of the strengthening support (it is shown in Fig. 2 by the shaded area).

The combination of specified two conditions makes it possible to ensure the stability of the drift during the formation of the minimum possible load on its fastening system (in specific mining and geological conditions), but this is identical to minimizing the materials intensity of means for fastening the extraction mine workings in the zone of stope works influence.

The specified two conditions are necessary, but not always sufficient in solving the problem of resource saving while optimizing the parameters of the fastening means of preparatory mine workings. The fact is that in the fastening system, where there are direct contacts or a structural connection between its separate elements and, accordingly, direct influence on each other of their deformation-strength characteristics, there are significant stresses concentrations in the areas of elements junction that are diversified by their operation modes. For example, when analysing the multivariate modelling results, a high concentration of the main stresses components was repeatedly noted in the area of the frame cap board contact with the central wooden prop stays of the strengthening support. These concentrations occurred both in the yielding frame cap board and in the rigid wooden prop stay, which, as a rule, was accompanied by either plastic deformations of the frame cap board (Fig. 3a) or by the destruction of the wooden prop stays of the strengthening support (Fig. 3b). 
$a$

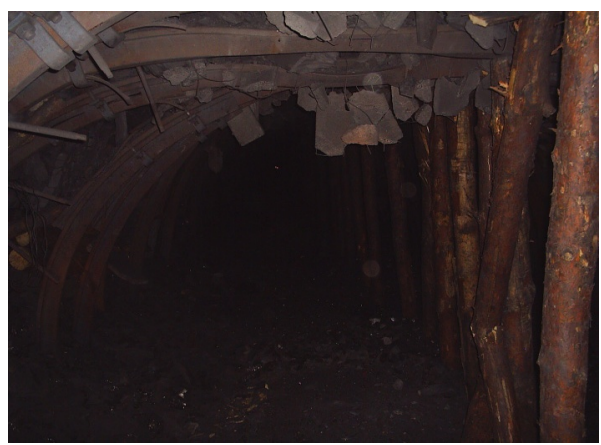

$b$

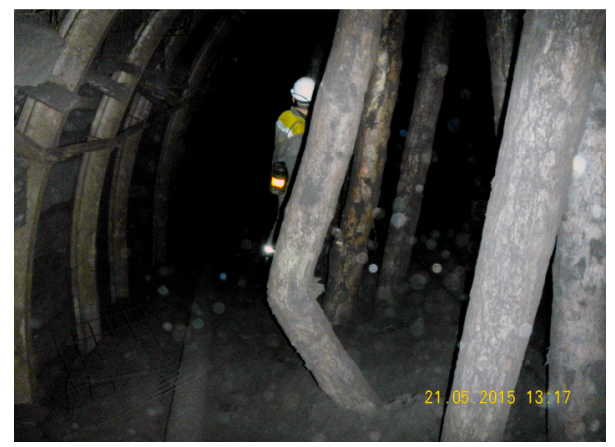

Fig. 3. The fragments of the fastening system state in the preparatory mine working in the zone of the stope works influence during the interaction of the yielding frame of the TSYS type and the rigid (wooden) central prop stay of the strengthening support: $\mathrm{a}$ - flattening of the frame cap board and $\mathrm{b}$ destruction of the central prop stays.

The focusing on this issue is conditioned by the fact that increased contact stresses in the areas of diversified load-bearing elements reduce their load-bearing capacity, as they cause the occurrence of the limiting and superlimiting state of the elements materials, while the prelimiting deformation takes place in other areas of the same elements. Thus, the main volume of fastening elements materials remain underloaded and their load-bearing capacity is reduced. In a certain sense, it can be referred to the unequal strength of separate fastening element. Therefore, an increase in the level of equal strength of each of the mating fastening elements is inextricably connected with the degree of coherency of their deformation-strength characteristics and in this term, this task becomes of primary importance. Here it is necessary to find a compromise between the two tendencies of the influence of the deformation-strength characteristics of separate fastening elements on their state: on the one hand, - the decrease in stresses concentrations in dangerous areas of the structure; on the other hand, the tendency to minimize the load on the fastening system as a whole and on its separate elements.

Summing up the results of the performed studies on the formation of concepts about the interaction of the coal-bearing massif with the fastening system of mine workings in the zone of the stope works influence, it should be noted that the developed qualitative schemes for optimizing their operation modes are the first stage of their transformation into a complex of quantitative patterns of interrelationship between geomechanical factors and deformation-strength characteristics of the fastening elements, which is the basis for developing the recommendations for improving the schemes for maintaining the reusable preparatory mine workings.

\subsection{Study of the influence of the central yielding hydraulic prop stay of the strengthening support}

In the course of the stress-strain state (SSS) analysis of different variants of fastening systems in the preparatory mine workings, it has been observed a negative impact of the rigid wooden prop stay of the strengthening support on the frame cap board. To develop the recommendations for improving stability of the cap board of the frame support, the computational experiments have been made using the finite element method (FEM) with the replacement of a wooden prop stay of the strengthening support with a yielding hydraulic prop stay, while maintaining the other equal conditions of the fastening system "frame - resin-grouted roof bolts and rope bolts in the roof". 
Analysis of the fastening system state has been carried out by three main components: vertical $\sigma_{y}$, horizontal $\sigma_{x}$ and stresses intensity $\sigma$. The curve of the vertical stresses $\sigma_{y}$ distribution in the elements of the fastening system with a central hydraulic prop stay is shown in Fig. 4 and is characterized by the following peculiarities. The frame cap board is exposed to the strongest influence of the operation mode of the central prop stay of the strengthening support. This influence has different intensity $\sigma_{y}$ along the cap board length. In its peripheral areas (near the yielding joists), the curve $\sigma_{y}$ is insignificantly changed in comparison with the variant of setting the wooden prop stays of the strengthening support. Thus, the main variation range $\sigma_{y}$ is from $1-2 \mathrm{MPa}$ of tension to $20-25 \mathrm{MPa}$ of compression, which does not exceed $7-9 \%$ of the value of estimated yield limit of SCP steel. The bending moment is minimal: in the area below the coordinates of the rope bolt tail joints location, the bending is directed towards the roof rocks; in the area above the tail joint - there is a deflection into the drift cavity. In general, a sufficient uniformity of $\sigma_{y}$ distribution in the cross section of the SCP and their low absolute values indicate a high degree of the cap board stability (according to the factor of vertical stresses action) in the peripheral areas with a length of up to $0.6 \mathrm{~m}$ from the side of the stope face and up to $0.7 \mathrm{~m}$ from the side of virgin massif.

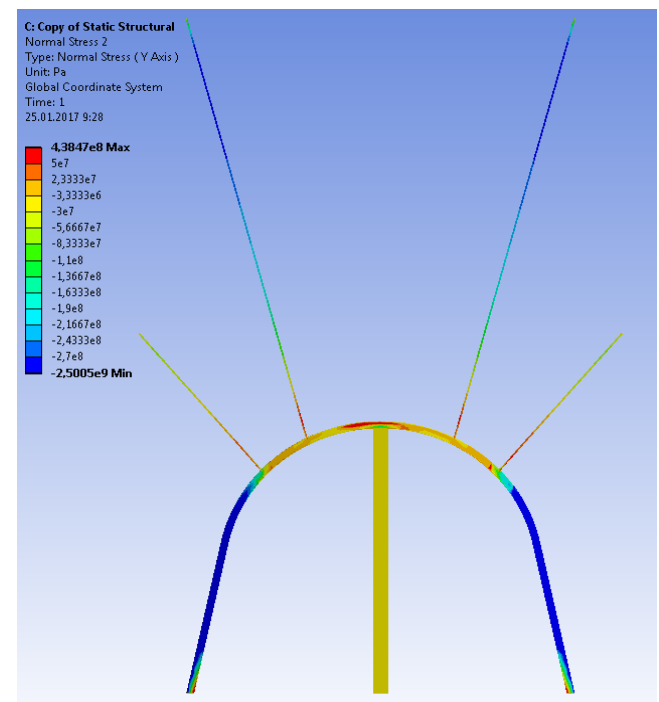

Fig. 4. The curve of vertical stresses $\sigma_{y}$ for the variant of fastening system with a central hydraulic prop stay.

In the central part of the cap board the situation is being changed dramatically: the certain perturbations $\sigma_{y}$ appear with some their asymmetry in the direction of the longwall face; this area takes a length of $0.7-0.8 \mathrm{~m}$. When approaching to a central hydraulic prop stay, the tensile stresses $\sigma_{y}$ increase up to $40-70 \mathrm{MPa}$, which is only $15-26 \%$ of the estimated yield limit of steel and does not constitute a danger to the cap board stability. Moreover, there is a differently vectored bending: from the side of virgin massif - into the mine working cavity; from the side of stope face - towards the roof. Directly in the area of contact with a hydraulic prop stay (across the width of up to $300 \mathrm{~mm}$ ), the direction of bending is observed towards the roof, however, the compressive stresses concentration $\sigma_{y}$ is low - only up to $50-80 \mathrm{MPa}(19-30 \%$ of the estimated yield limit of steel).

Thus, it has been established that when setting a hydraulic prop stay (yielding mode of operation), there is no "traditional" bend in the frame cap board, as it was observed in the 
variants with a rigid wooden prop stay of the strengthening support. The level of acting concentrations $\sigma_{y}$ is more than by 3 times less than the estimated yield limit of SCP steel, which is not only evidences the stable state of the frame cap board, but also confirms the expediency of using the yielding prop stays of the strengthening support, such as hydraulic prop stays, during the passage of the longwall face. Consequently, the accounting of the interaction modes of the fastening system elements (peculiarities are identified by the computational experiment results) makes it possible to radically change the state of the cap board according to the factor of vertical stresses action.

In the prop stays of the frame support, there are no significant changes in the curve $\sigma_{y}$ when comparing the variants with wooden and hydraulic prop stays of the strengthening support: in the upper part of the prop stays (near the yielding joists) with a length of 300 $350 \mathrm{~mm}$, the $\sigma_{y}$ increases from low tensile stresses (up to 20-30 MPa) to significant compressive stresses $(80-190 \mathrm{MPa})$, and when proceeding to a straight part of the prop stays, the $\sigma_{y}$ reaches $80-90 \%$ of the value of the estimated yield limit of SCP steel. In the straight part of the prop stays, the vertical stresses are stable, close, but do not reach the estimated yield limit of SCP steel. Such a state, close to the limiting one, indicates to high degree of their loading. However, almost uniform distribution of $\sigma_{y}$ in the cross section of the SCP minimizes the bending moment until its complete disappearance; this argument somewhat improves the prediction of the prop stays stability. In their lower part, at a height of up to $0.5 \mathrm{~m}$, a significant bending moment appears, which makes it possible to predict a high probability of bending the area of prop stays bearings into the mine working cavity.

The hydraulic prop stay, due to its work in the mode of almost constant resistance, is different by an extreme uniformity of the curve $\sigma_{y}$. The uniformity of the vertical compressive stresses up to $30 \mathrm{MPa}$ indicates the complete absence of the bending moment and any concentrations of $\sigma_{y}$ : the hydraulic prop stay works in favourable loading conditions, and its resistance reaction corresponds to the technical specification (see Fig. 4).

The combined roof-bolting system actively resists to the roof rocks lowering, and the distribution parameters $\sigma_{y}$ are somewhat different from those in comparison with the variant of setting the rigid wooden prop stays of the strengthening support.

It is quite predictable that a yielding hydraulic prop stay, providing a certain structurally included yielding property to the frame cap board, contributes to the redistribution of a part of its resistance to the combined roof-bolting system. An increase by $15-20 \%$ of tensile stresses occurs in resin-grouted roof bolts and rope bolts, but this is manifested only in the adjacent roof rock layer to a distance of $0.6-0.9 \mathrm{~m}$, and further along the length of the roof-bolts the differences in the curves $\sigma_{y}$ decrease. This fact can be explained as follows: it is well known, that the most active roof stratifications occur near the mine working contour, and it is here, that if the frame cap board 'deviates' from the increased rock pressure, then this difference should be compensated for by the resistance of other fastening elements, which in this case are resin-grouted roof bolts and rope bolts.

In general, according to the analysis results of the curve of vertical stresses distribution, two factors have been established related to the replacement of a rigid wooden prop stay with a yielding hydraulic prop stay of the strengthening support:

- the state of the frame cap board is being radically improved, its bend near the central prop stay is not predicted, since the maxima $\sigma_{y}$ are more than by 3 times lower than the estimated yield limit of SCP steel;

- the distribution of $\sigma_{y}$ in the rest fastening elements varies either insignificantly or in limited areas of the roof-bolts length.

To reduce the volume of this paper, the result of changes in the stresses components curves when setting a hydraulic prop stay is summarized by studying the stresses intensity field $\sigma$ in the main elements of the fastening system in mine working (Fig. 5). 


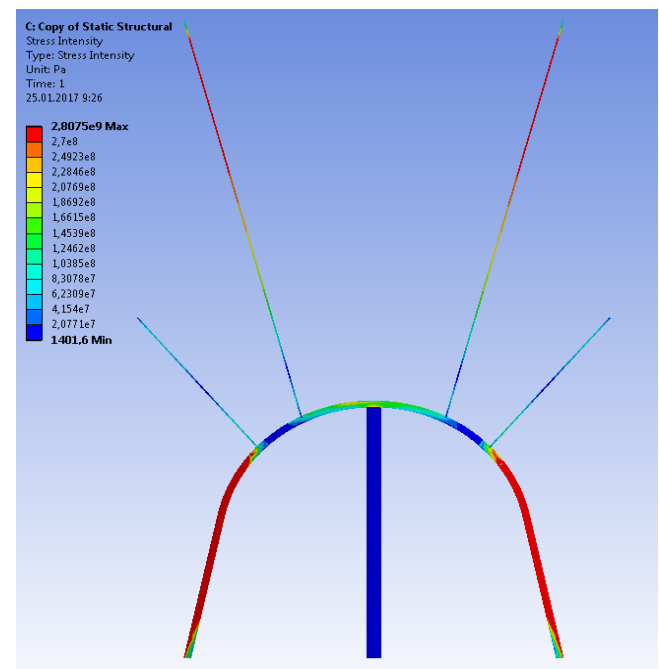

Fig. 5. The curve of stresses intensity $\sigma$ for the variant of fastening system with a central hydraulic prop stay.

As approaching to the central part of the mine working arch, the stresses intensity of a cap board increases up to $140-180 \mathrm{MPa}(52-67 \%$ of the estimated yield limit of SCP steel), but these values are far from dangerous. Moreover, a high degree of uniformity in $\sigma$ distribution over the area of SCP section of the cap board indicates the absence of any significant bending moment in these areas. A rather moderate bending moment appears in two areas of a cap board: directly in the area of contact with a hydraulic prop stay and in the area with length of $300-350 \mathrm{~mm}$, adjacent to the hydraulic prop stay from the side of stope face. Here the differential $\sigma$ in height of the SCP section is only $50-60 \mathrm{MPa}$, which is not able to form a significant bending moment, but it is clearly observed its sign change: from the side of the stope face, the deflection is directed into the mine working cavity, and directly on contact with the hydraulic prop stay - towards the roof rocks. In these areas, the maxima $\sigma=190-210 \mathrm{MPa}$, which is $70-78 \%$ of the estimated yield limit of SCP steel. Summing up the above data it can be claimed about the sufficient degree of the cap board stability with a considerable safety factor, which is not observed when setting the rigid wooden prop stays of the strengthening support (see Fig. 3a).

The frame support prop stays themselves are not almost exposed to the influence of operation modes of a hydraulic prop stay in terms of change in their curve of the stresses intensity $\sigma$ distribution. In the upper part of the prop stays, near the yielding joists of a frame, the $\sigma$ have a decreased value in the range of $40-120 \mathrm{MPa}$, but when approaching to the straight part of the prop stays, the stresses intensity reaches the dangerous values, amounting to $85-96 \%$ of the estimated yield limit of SCP steel. However, the distribution of $\sigma$ in the cross section of SCP is rather uniform (right up to the area of the prop stays bearings), which indicates the absence of any significant bending moment and makes possibility to predict the stable state of the prop stays, although close to the limiting state. In the area of bearings to a height of up to $0.4 \mathrm{~m}$, the disturbances $\sigma$ appear in the cross section of SCP, which indicate the occurrence of a significant bending moment, deforming the prop stay into the cavity of mine working. In general, the specified parameters of $\sigma$ distribution do not almost differ from the variant of setting a rigid wooden prop stay of the strengthening support. This case is explained by the fact that the hydraulic prop stays (regardless of the yielding mode of their work) have an active resistance to the vertical rock pressure, helping to the frame support prop stays at the same level as the central wooden prop stay. 
The distribution of $\sigma$ in a hydraulic prop stay is characterized by an extremely high uniformity both in cross section and in its height (see Fig. 5). The yielding operation mode contributes to a more complete "adaptation" of the prop stay to the nature of the rock pressure manifestations, which almost excludes the occurrence of any stresses concentrations. This peculiarity allows the hydraulic prop stay to develop a 'normal' resistance force in accordance with its technical characteristics.

In the combined roof-bolting system, which strengthen the rocks of the mine working roof, the stresses intensity distribution is very similar to the variant of setting a central wooden prop stay. It should be noted the high efficiency of the rope bolts to resist the displacements of the drift roof rocks. In the buried area (with length $52-57 \%$ of the total length of the roof-bolt), the stresses intensity is $77-98 \%$ of the value of estimated yield strength of the rope, and in its remaining length, the rope also actively prevents the roof rock stratifications.

The resin-grouted roof bolts at the boundaries of mine working arch work to constraint the stratifications of side rocks and create relatively holistic end areas of the armoured and rock plate above the entire mine working and beyond the limits of its width in the sides.

Thus, the SSS analysis results of the fastening system with the use of a yielding central hydraulic prop stay as a strengthening support convincingly prove the expediency of applying this prop stay in the direction of increasing the stability of the frame cap board without compromising the other fastening elements, making it possible to control their resistance to rock pressure manifestations.

\section{Conclusions}

Increasing the degree of coherency of the operation modes of rigid and yielding load-bearing elements of the fastening system in the preparatory mine working should be conducted in the direction of increasing the yielding property of a rigid element, which more sufficiently ensures the formation of a minimum possible load on the fastening system as a whole.

The reaction of the deformation-strength characteristics of the central prop stay of the strengthening support should be not less than the difference between the weight of the rocks inside the dome of natural equilibrium and the frame reaction according to the development of the rock contour displacements of the preparatory mine working as the longwall stope face approaches and recedes.

According to the results of the FEM research and SSS analysis of the fastening system in mine working when setting a hydraulic prop stay (yielding mode of operation), the following has been established:

- the plastic bend of the frame cap board, which was previously observed everywhere when setting the rigid wooden prop stays of the strengthening support, does not occur; the level of acting concentrations of vertical stresses $\sigma_{y}$ is more than by 3 times less than the estimated yield limit of SCP steel of the cap board, which proves the expediency of applying the yielding central prop stays of the strengthening support. The changes in the distribution of $\sigma_{y}$ in the remaining elements of the fastening system of mine working do not constitute a danger to its stable resistance to vertical rock pressure;

- a hydraulic prop stay, due to its work in the mode of constant resistance, removes the dangerous concentrations of horizontal stresses $\sigma_{x}$ and the very possibility of occurrence of plastic deformations in the cap board of the frame support. There was no a significant influence of changing the operation mode of the hydraulic prop stay on the curve of $\sigma_{x}$ distribution in the frame prop stays and in the combined roof-bolting system;

- the resulting assessment of the fastening structure by the value of the stresses intensity has confirmed the conclusion about the sufficient stability of the frame cap board (resists to the rock pressure with a considerable safety factor), which is not observed when setting the 
rigid wooden prop stays of the strengthening support. In general, the obtained results convincingly prove the expediency of applying the central yielding prop stays of the strengthening support with their setting in the preparatory mine working ahead of the zone of frontal rock pressure manifestation and their dismantling behind the longwall face in the zone of rock pressure anomalies stabilization.

The authors express their gratitude to the management of DTEK Coal Unit for their help in organizing the experimental research.

\section{References}

1. Kovalevska, I., Barabash, M., Husiev, O., \& Snihur, V. (2018). Interaction of deformationstrength characteristics of the support load-bearing elements in the preparatory workings. E3S Web of Conferences, (60), 00002. https://doi.org/10.1051/e3sconf/20186000002

2. Bondarenko, V., Kovalevska, I., Symanovych, H., Husiev, O., \& Snihur, V. (2019). Substantiation for Optimization of Load-Bearing Elements Interaction of the "Massif - Support" System in the Preparatory Mine Workings.

3. Symanovych, G., Astafiev, D., Vivcharenko, O., \& Snigur, V. (2015). Increasing of yielding of frame-anchor support steadiness. New Developments in Mining Engineering 2015: Theoretical and Practical Solutions of Mineral Resources Mining, 45-48. https://doi.org/10.1201/b19901-9

4. Dreus, A.Yu., \& Lysenko, K.Ye. (2016). Computer simulation of fluid mechanics and heat transfer processes at the working face of borehole. Naukovyi visnyk Natsional'noho Hirnychoho Unyversytetu, (5), 29-35.

5. Bondarenko, V., Kovalevskaya, I., Simanovich, G., Barabash, M., Snigur, V., \& Gusev, A. (2017). Kombinirovannye ankernye sistemy dlya povtornogo ispol'zovaniya gornykh vyrabotok. Dnipro: LizunovPres.

6. Bondarenko, V.I., Simanovich, G.A., Kovalevska, I.A., Fomichov, V.V., \& Serdiuk, V.P. (2007). Research of rock stresses and deformations around mining workings. Technical, Technological and Economic Aspects of Thin-Seams Coal Mining International Mining Forum 2007, 47-56. https://doi.org/10.1201/noe0415436700.ch6

7. Majcherczyk, T., Niedbalski, Z., Malkowski, P., \& Bednarek, L. (2014). Analysis of yielding steel arch support with rock bolts in mine roadways stability aspect. Archives of Mining Sciences, 59(3), 641-654. https://doi.org/10.2478/amsc-2014-0045

8. Małkowski, P., Ostrowski, Ł., \& Brodny, J. (2018). Analysis of Young's modulus for Carboniferous sedimentary rocks and its relationship with uniaxial compressive strength using different methods of modulus determination. Journal of Sustainable Mining, 17(3), 145-157. https://doi.org/10.1016/i.jsm.2018.07.002

9. Małkowski, P., \& Ostrowski, Ł. (2017). The Methodology for the Young Modulus Derivation for Rocks and Its Value. Procedia Engineering, (191), 134-141. https://doi.org/10.1016/j.proeng.2017.05.164

10. Stanisz, J., Borecka, A., Pilecki, Z., \& Kaczmarczyk, R. (2017). Numerical simulation of pore pressure changes in levee under flood conditions. E3S Web of Conferences, (24), 03002. https://doi.org/10.1051/e3sconf/20172403002

11. Majcherczyk, T., Pilecki, Z., Niedbalski, Z., Pilecka, E., Blajer, M., \& Pszonka, J. (2012). The Influence of Geological Engineering and Geotechnical Conditions on Parameter Selection of the Primary Lining of a Road Tunnel in Laliki. Gospodarka Surowcami Mineralnymi - Mineral Resources Management, 28(1). https://doi.org/10.2478/v10269-012-0006-2

12. Grigoriev, O., Tereschuk, R., \& Tokar, L. (2015). Assessment of efficiency AMS-A (anchor meshwork - shotcretihg) support structure in terms of coal mines. New Developments in Mining Engineering 2015: Theoretical and Practical Solutions of Mineral Resources Mining, 85-89. https://doi.org/10.1201/b19901-17

13. Kovalevskaya, I.A. (2003). Geomekhanika vzaimodeystviya elementov sistemy "gornyy massiv uprochnennye porody - krep' podzemnykh vyrabotok”. Dnipropetrovsk: NHA Ukrainy. 
14. Pytlik, A., Prusek, S., \& Masny, W. (2016). A methodology for laboratory testing of rockbolts used in underground mines under dynamic loading conditions. Journal of the Southern African Institute of Mining and Metallurgy, 116(12). http://dx.doi.org/10.17159/2411-9717/2016/v116n12a2

15. Kovalevskaya, I.A., \& Simanovich, G.A. (2006). Geomekhanika vzaimodeystviya bezzamkovoy ankernoy krepi s porodnym massivom. Dnepropetrovsk: Sistemnye tekhnologii.

16. Madziarz, M. (2015). Improvements in methods for monitoring anchor casings in mining excavations of KGHM Polska Miedź S.A. mines. Mining Science, (22), 115-125. https://doi.org/10.5277/msc152210

17. Baklashov, I.V., \& Kartoziya, B.A. (1975). Mekhanika gornykh porod. Moskva: Nedra.

18. Kovalevska, I., Symanovych, G., \& Fomychov, V. (2013). Research of stress-strain state of cracked coal-containing massif near-the-working area using finite elements technique. Annual Scientific-Technical Collection - Mining of Mineral Deposits 2013, 159-163. http://dx.doi.org/10.1201/b16354-28

19. Khomenko, O.Ye., Sudakov, A.K., Malanchuk, Z.R., \& Malanchuk Ye.Z. (2017). Principles of rock pressure energy usage during underground mining of deposits. Naukovyi Visnyk Natsionalnoho Hirnychoho Universytetu, 2(158), 34-43.

20. Bondarenko, V., Symanovych, H., Kicki, J., Barabash, M., \& Salieiev, I. (2019). The influence of rigidity of the collapsed roof rocks in the mined-out space on the state of the preparatory mine workings. Mining of Mineral Deposits, 13(2), 27-33. https://doi.org/10.33271/mining13.02.027

21. Kovalevska, I., Zhuravkov, M., Chervatiuk, V., Husiev, O., \& Snihur, V. (2019). Generalization of trends in the influence of geomechanics factors on the choice of operation modes for the fastening system in the preparatory mine workings. Mining of Mineral Deposits, 13(3), 1-10. https://doi.org/10.33271/mining13.03.001

22. Bondarenko, V., Kovalevs'ka, I., Svystun, R., \& Cherednichenko, Y. (2013). Optimal parameters of wall bolts computation in the united bearing system of extraction workings frame-bolt support. Annual Scientific-Technical Collection - Mining of Mineral Deposits 2013, 5-9. http://dx.doi.org/10.1201/b16354-3

23. Bulat, A.F., \& Vinogradov, V.V. (2002). Oporno-ankernoe kreplenie gornykh vyrabotok. Dnipropetrovsk: Vilpo.

24. Skipochka, S., Krukovskyi, O., Serhiienko, S., Krasovskyi, I. (2019). Non-destructive testing of rock bolt fastening as an element of monitoring the state of mine workings. Mining of Mineral Deposits, 13(1), 16-23. https://doi.org/10.33271/mining13.01.016

25. Bondarenko. V., Kovalevska, I., Symanovych, H., Barabash, M., \& Vivcharenko, O. (2018). Geomechanics of mine workings support systems. Dnipro: CRC Press/Balkema.

26. Bondarenko, V., Kovalevs'ka, I., \& Fomychov, V. (2012). Features of carrying out experiment using finite-element method at multivariate calculation of "mine massif - Combined support" system. Geomechanical Processes during Underground Mining - Proceedings of the School of Underground Mining, 7-13. https://doi.org/10.1201/b13157-3

27. Kovalevs'ka, I., Vivcharenko, V., Snigur, V. (2013). Specifics of percarbonic rock mass displacement in longwalls end areas and extraction workings. Annual Scientific-Technical Collection - Mining of Mineral Deposits 2013, 29-33. https://doi.org/10.1201/b16354-6

28. Bondarenko, V., Kovalevs'ka, I., \& Ganushevych, K. (2014). Progressive Technologies of Coal, Coalbed Methane, and Ores Mining. https://doi.org/10.1201/b17547

29. Malanchuk, Z.R. (2019). Substantiating parameters of zeolite-smectite puff-stone washout and migration within an extraction chamber. Naukovyi Visnyk Natsionalnoho Hirnychoho Universytetu, (6). Article in press.

30. Lozynskyi, V., Saik, P., Petlovanyi, M., Sai, K., \& Malanchuk, Z. (2018). Analytical Research of the Stress-Deformed State in the Rock Massif around Faulting. International Journal of $\begin{array}{lllll}\text { Engineering Research in } & \text { 7frica, }\end{array}$ https://doi.org/10.4028/www.scientific.net/jera.35.77 